Review Article

\title{
ROLE OF MICROSPHERES IN NOVEL DRUG DELIVERY SYSTEMS: PREPARATION METHODS AND APPLICATIONS
}

\author{
VASUNDHRA KAKKAR ${ }^{1}$, SHAHID UD DIN WANI ${ }^{1 *}$, SURYA PRAKASH GAUTAM ${ }^{1}$, ZULFKAR LATIEF QADRIE ${ }^{2}$ \\ 1,2Department of Pharmaceutics, CT Institute of Pharmaceutical Sciences, CT Group of Institutions, Jalandhar, India 144020 \\ Email: shahidpharma2013@gmail.com
}

Received: 25 Jan 2020, Revised and Accepted: 23 Mar 2020

\begin{abstract}
Microsphere based drug delivery system has gained substantial attention in the modern era. Microspheres are normally free-flowing powders that can be made with both natural and synthetic polymers. The sizes of the microspheres ranges from 1 to $1000 \mu \mathrm{m}$. Microspheres are matrix systems in which the drug is uniformly dispersed, dissolved or suspended. Microspheres contain solid or liquid drug dissolved or dispersed in a matrix system. The current review provides an inclusive outline of up to date and novel developments on formations of microspheres which have been reported to increase bioavailability, improves stability, enhances biological half-life and reduces the toxicity of the drug. Microsphere provides efficient delivery of various proteins and peptide molecules. There are different types of microspheres such as bio adhesive microsphere, magnetic microsphere, floating microsphere, and polymeric microspheres. Diverse kinds of methods are used in the formulation of microsphere e. g. Simple emulsion-based method, Double emulsion-based method, Interfacial deposition technique, Interfacial polymerization technique, Phase separation method, and Spray drying. Microspheres deliver the drug in a controlled manner through different routes like oral, topical, naso-pulmonary and gene therapy. The Polymeric based microspheres are model carriers for numerous controlled delivery applications owing to their capacity to encapsulate a diversity of drugs, bio-compatibility, high bio-availability and continuous drug release character. Therefore, by developing newer techniques, it can give more therapeutic effects and improves the safety of drugs. The formation of microspheres has been reported to increase bioavailability, improves stability, enhances biological half-life and reduces the toxicity of the drug.
\end{abstract}

Keywords: Microspheres, Drug delivery, Polymeric, Improved stability

(C) 2020 The Authors. Published by Innovare Academic Sciences Pvt Ltd. This is an open access article under the CC BY license (http://creativecommons.org/licenses/by/4.0/) DOI: http://dx.doi.org/10.22159/ijcpr.2020v12i3.38326. Journal homepage: https://innovareacademics.in/journals/index.php/ijcpr

\section{INTRODUCTION}

A drug proposed for clinical use must have an optimal therapeutic index (ratio of minimum effective to the maximum safe concentration of drug). Many chemotherapeutic agents have a narrow therapeutic window leads to restricted clinical use and increased toxic side effects. So, these kinds of drugs are incorporated in a polymer system, which ensures the controlled release of drugs to provide optimum drug levels at the target site [1]. Numerous targeted drug delivery systems have come up with different techniques to attain controlled and targeted drug delivery. Microsphere based targeted drug delivery system is gaining substantial importance in the modern era [2].

The size of microspheres ranges from 1 to $1000 \mu \mathrm{m}$. Microspheres are matrix systems containing active ingredient uniformly dispersed, dissolved or suspended. Microspheres contain solid or liquid drug dissolved or dispersed in a matrix system [3]. Microspheres of size less than $800 \mu \mathrm{m}$ pass through the pyloric sphincter without any effect of gastric emptying, thereby excluding the inter-individual variations. Microsphere particles of size above $100 \mathrm{~nm}$ remain at the administering site till phagocytic clearance. Microspheres uptake by the lymphatic system were notably between the size ranges from 10-80 nm [4]. The surface charge plays a significant role in the aggregation of particles. Aggregation of particles leads to a decrease in the uniformity of dose and disturbs the normal flow of blood $[5,6]$.

\section{Advantages of microspheres}

Microspheres suggests several advantages over conventional methods of drug delivery, as well as couture of medicine release rates, safeguard of delicate drugs and augmented patient ease and acquiescence. Also, Enhances solubility of the lipophilic drugs, constant plasma drug concentration is achieved, reduced dose size, dosing frequency and side effects, polymer coating prevents the drug from enzymatic degradation, bioavailability of the drug is improved, improves stability of drug, enhance biological half-life of drug, reducing toxicity, and protects the GIT from the drugs which produce gastric irritation [6].

\section{Disadvantages of microspheres}

Some of the disadvantages of microsphere-based drug delivery can be that once injected, it is hard to remove from the body if the drug produces some adverse toxic effects. Also, Dosage form containing microspheres should be handled with care, not to be crushed or chewed. The Release rate might differ from one dose to another. Gastric contents and GI transits might modify the release of drug [2].

\section{Drug release mechanism through microspheres}

The drug diffusion occurs throughout the integral polymer system or the pores filled with aqueous fluid. Hydrophilic drugs may get dissolved in the pores containing aqueous fluid. Uptake of aqueous fluid causes polymer network to swell, indicates the building of new pores and osmotic pressure. Swelled polymer increases the volume; therefore, helpful diffusion coefficient of the drug is also improved, and more drug molecules go into the aqueous phase. The polymer matrix may also get eroded from the bulk or surface of microspheres $[7,8]$.

\section{Types of microspheres}

\section{Mucoadhesive/Bioadhesive microspheres}

Adhesion of microspheres on any mucosal membrane (e. g. ocular, vaginal, oral, buccal, rectal, and nasal) is termed as Bioadhesion/Mucoadhesion. Adhesion of microspheres at the target site will increase the duration of action of a drug and thus improves the bioavailability. Natural or synthetic polymers used to produce adhesion to the biological membrane. Mucoadhesive polymers improve the contact time of the microspheres with the mucous membranes; absorption of the drug takes place through mucosa $[9$, 10]. Mucin turnover is likely to restrict the residence time of the bioadhesive microspheres on the mucus membrane and it does not depend upon the strength of the mucoadhesive polymers [11]. 
Fluoxetine is an antipsychotic drug that considerably undergoes first-pass hepatic metabolism. Therefore mucoadhesive microspheres were formed to improve bioavailability and sustain the drug release by increasing the residence time of the drug in the gastrointestinal tract $[12,13]$.

\section{Magnetic microspheres}

Magnetic microspheres are tiny particles which freely move through blood vessels without producing any obstruction, they are susceptible to be arrested in any vessel and extravasate into tissues by magnetic field of $0.5-0.8$ tesla. In response to the external magnetic field magnetic microspheres reaches the target site and releases the drug [14]. In this system, drug can be either encapsulated in the polymer (silica or hydroxyl apatite) or attached to the microsphere surface. Magnetic core of the microspheres consists of magnetite, magnetic ferrites (cobalt ferrite or manganese ferrite). Magnetic microspheres are used in targeting of anticancer drugs (paclitaxel, mithotrixate doxorubicin, cisplatin). Magnetic microspheres are used for extraction of stem cells and also used in isolation of DNA, cell organelles, cells or proteins [14]. The content of magnetic material and the extent of magnetic field applied govern the retention of microspheres at the targeted site [15].

\section{Floating microspheres}

These microspheres are kind of gastro retentive systems which prolongs the drug residence time in stomach having size of less than 200 micrometer [16]. The drugs used may produce local action in the stomach (antacids, antibiotics for ulcers caused by H. Pylori bacteria) or likely to be absorbed though stomach (albuterol, amoxicillin). These are hollow microspheres or microballons designed to float on the gastric fluid with the density of less than one. Various polymers used in the formulation of floating microspheres are chitosan, polyvinyl acetate, eudragit, agar, acrylic resins, polyacrylates. These polymers in the presence of gastric juices swells to form a colloidal gel barrier from which drug is released in controlled manner, air gets trapped in the swollen polymer which reduces the density of the system and impart buoyancy to the microspheres [17]. Bhadouriya et al. (2014) developed and evaluated a floating drug delivery system containing clopidogrel bisulphate to increase bioavailability and to reduce the side effects caused by the drug like development of drug resistance and gastric bleeding $[18,19]$.

\section{Radioactive microspheres}

These are radiolabeled microspheres used for targeting the drugs to tumors in cancer treatment. Radiolabeled microspheres are very stable and have proven efficacy in the field of primary and secondary cancers without any effect of radiation over the normal tissues. Radioactive microspheres are injected in the blood capillaries near to the tumor [20]. They contain one or more radionuclides, radioactivity in contrast to drugs never released from the microspheres but acts from within a typical radioisotope distance. Radio microspheres are of different kinds containing alpha emitters, beta emitters and gamma emitters [21]. The type of materials used for making radio microsphere are glass (aluminosilicate, Lithium silicate), albumin (human or bovine serum albumin),resins (aminex A-27, aminex A-5), polymers(polylactic acid, polyglycolic acid) [20, 22]. Yttrium-90(beta emitter) microspheres may help to treat the liver cancer by destroying the tumor cells though radiations [23].

\section{Polymeric microspheres}

It mainly consist of polymer and drug, also contain a block co-polymer which prevent the opsonization (linking of opsonin with the microsphere to facilitate its phagocytosis) of drug delivery system. Polymeric microspheres are coated with recognition molecules such as an antigen, nucleic acid probes, and antibodies can be loaded with lipophilic dyes and other compounds. Different kinds of polymers can be used to direct the release of drugs to a particular organ [24].

\section{Classification of polymeric microspheres}

\section{Biodegradable polymeric microspheres}

Natural polymer like starch has biodegradable, biocompatible, and bio adhesive properties. Concentration of the polymer used may affect the bioavailability of drug. Its disadvantage is, in clinical use loading efficiency of drug in biodegradable micro-spheres is complicated and the drug release is hard to be controlled [25].

\section{Synthetic polymeric microspheres}

They are used clinically and are also used as bulking agent (used to treat stress urinary incontinence), soft tissue fillers (used in correcting lips, wrinkles and scars), embolic particles (used in the treatment of cancer), and drug delivery vehicles. Disadvantage of synthetic polymeric microspheres is, they likely to move away from site of injection and may cause embolism and organ damage [26].

\section{Natural polymers}

Obtained from different sources like carbohydrates (E. g. Agarose, Chitosan, Carrageenan, Starch), Proteins (E. g. Albumin, Collagen, Gelatin, Silk fibroin) and chemically modified Carbohydrates (E. g. Poly acryl dextran, Poly acryl starch, DEAE cellulose) [27, 80, 81].

\section{Synthetic polymers}

They are divided into two types. Biodegradable polymers (E. g. Lactides, Glycolides and their co-polymers, Poly anhydrides, Polyalkyl cyano acrylates, another is Non-biodegradable polymers (E. g. Poly methyl methacrylate (PMMA), Glycidyl methacrylate, Epoxy polymers, Acrolein) [28].

\section{Methods to formulate microspheres}

\section{Simple emulsion-based method}

Several carbohydrates and proteins are prepared by this method. In this natural polymers are solubilized in aqueous medium and then dispersed in organic solvent. Next step is cross-linking of polymer which is carried out by following methods-

\section{Heat cross-linking}

In this, dispersion is added into previously heated non-aqueous phase; therefore it is unsuitable for the Thermo labile drugs.

\section{Cross-linking by chemical agents}

Formaldehyde, di-acid chloride, glutaraldehyde are used for cross linking of polymers. The problem of using these agents during preparation is that microspheres must be properly centrifuged and then washed to remove chemical residues. Solution of chitosan in acetic acid is poured into previously heated Liquid paraffin containing a surfactant resulting formation of w/o emulsion [29]. Metformin HCL microspheres were prepared by using $25 \%$ glutaraldehyde solution [30].

\section{Double emulsion-based method}

This method helps forming w/o/w type emulsion by adding the primary w/o emulsion into polyvinyl alcohol solution and stirred for half an hour. Now slowly add the water into the emulsion over a period of half an hour. Microspheres were then collected, filtered and vacuum dried [31]. This method is best for hydrophilic drugs, peptides, vaccines and proteins. Both natural and synthetic polymers are used in the formation of microspheres by this method [32].

\section{Polymerization technique}

The two techniques used to prepare microspheres are classified as:

\section{Normal polymerization}

This method includes heating of a single monomer or mixture of monomers along with the initiator or catalyst to initiate polymerization. Polymer so obtained may be mounded into microspheres. Drug is added during the process of polymerization. Heat of reaction is difficult to dissipate, which may affect the pharmacological activity of thermolabile drugs. Lower temperature conditions are involved in suspension polymerization in which the monomer mixture is heated with active drug as droplets dispersion in the continuous aqueous phase. Microspheres of size less the 100 $\mu \mathrm{m}$ are obtained by suspension techniques. Emulsion polymerization contains initiator in aqueous phase and it is also carried out at low temperature as suspension polymerization. 
External phase is normally used as water so that heat can easily dissipate. Polymers might form at higher rate by these techniques but polymer can get associated with the unreacted monomer or other additives [32].

\section{Interfacial polymerization}

In this technique, polymerization occurs at the interface between the two immiscible liquid phases to form a film of polymer that effectively encapsulates the dispersed phase. Two reacting monomers are used; one was dissolved in continuous phase while other was dispersed in a continuous phase throughout which the second monomer is emulsified. Two conditions were raised depending upon solubility of the formed polymer in the emulsion droplet that is if formulation formed is of the monolithic type the polymer was soluble in droplet and capsular type if the polymer was insoluble in droplet [30,32].

\section{Spray drying and congealing method}

Spray drying is an extensively used industrial process involving the formation of microspheres. In this method, polymer solution, drug and solvent is atomized into a fine spray with help of atomizer. Hot stream of gas is passed through the sprayed droplets, which results in evaporation of liquid and forming dried microsphere particles. In spray drying the finished product must fulfill some specific quality standards regarding particle size, net moisture content, bulk density, and shape of microspheres.

In spray congealing method, drug is dissolved or suspended in melted excipients and atomized into cold nitrogen leading to solidification of droplets and microsphere formation. Spray congealing is a solvent-free process [33-35].

\section{Wax coating and hot melt}

In this, the polymer is dispersed in appropriate medium and gradually cooled to prepare microspheres. The polymers used should have low melting point [36]. Wax is used to form core and coat of the particle and the drug is dispersed in the molted wax. The wax suspension is dispersed into cold solution, for example, liquid paraffin with high speed mixing. Agitation is continued for one hour and then continuous phase was decanted and microspheres were collected. Microspheres were then air-dried. It is not an expensive method as a comparison to other methods and the release of drug is more rapid. Carnauba wax and beeswax can be used as the coating materials and there mixture can be used in order to achieve desired characteristics [37].

\section{Ionotropic gelation method}

In this method, sodium alginate and eudragit are the polymers used. To prepare microspheres polymers and drug is dispersed in sodium alginate solution and added dropwise in calcium chloride solution with continuous stirring. These microspheres help providing sustained release of drugs and increase the dosing interval [38].

\section{Solvent evaporation method}

Degradation of proteins and peptides can be prevented by encapsulating them in microspheres through this technique [39]. Microspheres are formed by dissolving eudragit polymer in organic solvent (for e. g. chloroform) to form a uniform polymer solution. Required amount drug can be added to this polymer solution and mixed thoroughly; this mixture was then added to aqueous mucilage of sodium carboxymethyl cellulose containing tween 80 and stirr at $1000 \mathrm{rpm}$. Organic solvent was removed by evaporation with continuous stirring at room temperature. Sodium carboxymethyl cellulose acts as a microencapsulating agent and tween 80 as a surfactant [40].

\section{Coacervation phase separation method}

Researchers have been investigated the use of cellulose acetate phthalate and cellulose acetate as polymers [41-43] using organic solvents [44-46] in microencapsulation of a drug-using this method. To form microspheres the drug is added to liquid paraffin previously containing polysorbate. Polymer solution is made by dissolving polymer in organic solvent and added to the drug mixture with continuous stirring until solvent gets evaporated at room temperature.

\section{Applications of microspheres \\ Microspheres used for vaccine delivery}

Vaccine provides protection by developing resistance against infectious diseases. Some examples of vaccines encapsulated in microspheres are tetanus vaccine, diphtheria vaccine, cholera vaccine [47]. Microspheres containing vaccines improve immunologic response by prolonging the antigen release for weeks to even months [48, 49]. Degradation of vaccine is prevented by encapsulating it in a suitable carrier until it gets released. The controlled delivery of vaccine may diminish systemic side effects and can encapsulate multiple antigenic epitopes or both antigen and adjuvant in a single carrier. Biodegradable polymers are used for the sustained release of encapsulated antigen and which degrade in the body to nontoxic, low-molecular-weight products that can be easily eliminated [50]. Chitosan microspheres are capable to encapsulate a wide range of antigens. Synthetic biodegradable polymers such as poly lactic-coglycolic acid is the best option and mostly used for antigen encapsulating single-shot vaccines [51].

\section{Microspheres containing monoclonal antibodies}

(Mabs)-Monoclonal antibodies have high specificity for antigen molecules present at the target site [52]. Specificity of monoclonal antibodies is used for targeting microspheres carrying pharmacologically active molecules to target sites. Covalent coupling, nonspecific adsorption, coupling via reagents, specific adsorption are methods used to attach monoclonal antibodies with microspheres. The free carboxyl group, aldehyde groups, amino groups or hydroxyl groups on the surface of the microspheres can be linked to the antibodies [53]. Microspheres carrying anti-vascular endothelial factor formulation (containing monoclonal antibodies) showed release up to six months [54].

\section{Microspheres in gene delivery}

For delivery of genes, mostly recombinant adenoviruses are used because of their high efficiency and have an extensive range of cell targets, though when used in vivo they generate immune responses and oncogenicity. Also, repeated gene therapy is required when viral vectors are used. In non-viral gene delivery microspheres are used to encapsulate genes, provides sustained gene delivery [55]. Microspheres are stable, easy to prepare, target the cells/tissue, generate low immune responses, and large-scale reproducible production is also possible.

\section{Ophthalmic drug delivery through microspheres}

Polymers used for ophthalmic drug delivery imparts bio adhesion, and permeability-enhancing properties. Polymer hydrogels are more effective due to their elasticity as compare to other formulations for ophthalmic drug delivery such as ointments or suspensions. A Chitosan gel improves adhesion to the mucin membrane, spreads over the conjunctiva and the corneal surface of the eye and precorneal drug residence times is increased by preventing the elimination of drug through lachrymal flow. Drug loaded microspheres can be suspended in a polymer hydrogel system to achieve sustained or controlled delivery of drug in eye $[53,56]$.

\section{Nasal drug delivery though microspheres}

The nasal mucosa is an ideal site for bioadhesive drug delivery systems. Microspheres are created to have good bioadhesive properties and swell easily in contact with the nasal mucosa improving the bioavailability and residence time of the drugs in the nasal route. Various polymer salts such as chitosan lactate, chitosan aspartate, chitosan glutamate and chitosan hydrochloride are good candidates for nasal sustained release of vancomycin hydrochloride. Nasal administration of chitosan microspheres containing diphtheria toxoid produces a defensive local and systemic immune response against the toxoid by enhancing the production of IgG antibodies [57]. Microspheres absorb the moisture present in mucosa results in shrinking of the nasal cells cause short term separation of tight junction through which absorption of drug is increased [58]. Dextran and starch microspheres are considered to be safe for nasal drug 
delivery [59]. Alginate Microspheres containing ondansetron prepared by Ionic-gelation method used to sustain the drug release for extended time period though nasal mucosa [60].

\section{Microspheres for delivery of protein and peptides}

Microspheres made up of biodegradable polymers were studied for their controlled release of proteins and peptides. Microspheres help to maintain steady-state plasma concentration of protein or peptide for long periods of time [61]. Bio-degradable polylactic acid and polylactic-co-glycolic acid and chitosan microspheres are applicable in microsphere formulation of protein/peptide drugs [62]. Marketed peptide drugs like, triptorelin, lanreotide, buserelin, and abarelix use the microsphere-based delivery system [63].

\section{Microspheres used in cancer treatment}

Radioactive microspheres containing $\beta$-emitter (e. g. yttrium-90) used for targeting tumors present in liver.
Suspension of radioactive microspheres is injected into the hepatic artery, microspheres having a diameter of 30 micron gets into the tumor vessels. Tumor cells get destroyed after getting exposed to radiations without destroying neighboring normal cells [64]. Polymeric microspheres containing 5fluorouracil drug can be used to treat colon cancer. These polymeric microspheres protect the drug from getting degraded in the gastric environment.

\section{Marketed formulations of microspheres}

Various marketed formulations of microsphere are as given in (table $1)$, with their active agents and for use in disease condition [9, 65-67].

\section{Some of the patents on microsphere formulations}

Various patents on Microsphere Formulations are available based on the type of formulation used in drug delivery, which is given in (table 2).

Table 1: Marketed formulations of microspheres

\begin{tabular}{|c|c|c|c|}
\hline Dosage form & Active ingredient & Disease condition & Marketed products \\
\hline Injectable suspension (i. m.) & Naltrexone & Alcoholism, opoid dependency & Vivitrol $\AA$ \\
\hline Injectable suspension (i. m.) & Respiridone & Schizophrenia & Risperdal $®$ consta $®$ \\
\hline Powder for injection (s. c.) & Somatropin & Growth hormone deficiency & Nutropin $®$ Depot \\
\hline Powder for Injection (i. m) & Bromocriptine & Parkinson`s disease, Acromegaly & Parlodel $囚$ LAR \\
\hline $\begin{array}{l}\text { Powder for suspension for injection (s. } \\
\text { c, i. m) }\end{array}$ & Triptorelin & Advanced prostate cancer & Decapeptyl $\AA$ \\
\hline Injection (s. c) & Buserelin & Prostate cancer & Suprecur® MP \\
\hline $\begin{array}{l}\text { Extended-release injectable } \\
\text { Suspension (s. c.) }\end{array}$ & Exenatide & Type-2 Diabetes mellitus & Bydureon® \\
\hline Injectable suspension (i. m.) & Lanreotide & $\begin{array}{l}\text { Acromegaly, Gastroenteropancreatic } \\
\text { Neuroendocrine tumors, Thyrotropic adenomas }\end{array}$ & Somatuline $®$ LA \\
\hline Implant or Injectable suspention (s. c.) & Goserelin acetate & Prostatic carcinoma, Endometriosis & Zoladex® \\
\hline $\begin{array}{l}\text { Injectable suspension } \\
\text { (Intragluteal inj.) }\end{array}$ & Octreotide & $\begin{array}{l}\text { Acromegaly, carcinoid tumor, vasoactive intestinal } \\
\text { peptide tumors }\end{array}$ & Sandostatin LAR® \\
\hline Powder form & Minocycline & Periodontitis & Arestin $\AA$ \\
\hline Suspension depot injection & Leuprolide acetate & Endometriosis & Lupron $®$ depot \\
\hline
\end{tabular}

Table 2: Various patents on microsphere formulations

\begin{tabular}{|c|c|c|c|}
\hline Patent title & Patent number & Year & References \\
\hline Microspheres for controlled-or sustained-release delivery of therapeutics & US 9,381,159 B2 & 2016 & [68] \\
\hline Microspheres for Treatment of Brain Tumors & US $8,691,791 \mathrm{~B} 2$ & 2014 & [69] \\
\hline Programmable buoyant delivery technology & US2010/0015224A1 & 2010 & {$[70]$} \\
\hline Magnetic Microspheres for Use in Fluorescence-Based Applications. & US 7,718,262 B2 & 2010 & [71] \\
\hline Gastroretentive controlled-release microspheres for improved drug delivery & US006207197B1 & 2001 & [72] \\
\hline Metal-Coated Polyaldehyde Microspheres & $4,624,923$ & 1986 & [73] \\
\hline Porous wall hollow glass microspheres as carriers for biomolecules & US2012/0201892A1 & 2012 & [74] \\
\hline Bioadhesive Microspheres and their Use as Drug Delivery and Imaging Systems & US 6,235,313 B1 & 2001 & [75] \\
\hline Polymeric Microspheres & US 6,720,007 B2 & 2004 & [76] \\
\hline $\begin{array}{l}\text { Process for Preparing Microspheres for Prolonged Release of the LHRH Hormone and its Analogues, } \\
\text { Microspheres and Formulations Obtained }\end{array}$ & $5,540,937$ & 1996 & {$[77]$} \\
\hline Production of Microspheres & US 7,374,782 B2 & 2008 & [78] \\
\hline Compositions and methods for treating intracellular infections & US 6,264,991 B1 & 2001 & [79] \\
\hline
\end{tabular}

\section{CONCLUSION}

Microspheres have revealed immense promise for the delivery of remedial agents owing to their biocompatibility, easiness of administration and potential for lasting sustained release. Additionally, microspheres are valuable for delivering numerous types of compounds, as well as small molecule drugs, vaccines, gene therapy agents and protein therapeutics. For past several years of studies, it has been exhilarating development in methods of production, managing of drug release rates and particularly stabilization of the encapsulated materials. In the coming decade, the development in macro-molecular pharmaceuticals will compel more advances in particle fabrication and drug encapsulation techniques, in addition to common methods of stabilizing protein and gene therapeutics. Improvements in developed technologies, novel strategy for stabilization of delicate therapeutics and progress of novel approaches for site-specific particle targeting will ensure that microspheres play a significant job in the drug delivery field in the coming decade, too.

\section{ACKNOWLEDGMENT}

Authors thank The Director, CT Institute of Pharmaceutical Sciences, Jalandhar and The Management, CT Group of Institutions, Jalandhar for their continuous support and motivation.

\section{FUNDING}

Nil

\section{AUTHORS CONTRIBUTIONS}

All the authors have contributed equally. 


\section{CONFLICT OF INTERESTS}

The authors declare no conflict of interest, financial or otherwise.

\section{REFERENCES}

1. Vyas SP, Khar RK. Targeted and controlled drug delivery: novel carrier systems. CBS Publishers, New Delhi; 2002.

2. Ganesan P, Jonson AJD. Review on microspheres. Am J Drug Discovery Dev 2014;4:153-79.

3. Whelehan M, Marison IW. Microencapsulation using vibrating technology. J Microencapsul 2011;28:669-88.

4. Yang Q, Forrest L. Drug delivery to the lymphatic system. In: Wang B, Hu L, Siahaan TJ. editors. Drug Delivery Principles and Applications. 2nd ed. Hoboken: John Wiley and Sons Inc; 2016. p. 503-48.

5. Desai T, Shea LD. Advances in islet encapsulation technologies. Nat Publ Gr 2016;16:338-50.

6. Virmani T, Gupta J. Pharmaceutical application of microspheres: an approach for the treatment of various diseases. Int J Pharm Sci Res 2017;8:3252-60.

7. Prajapati VD, Jani GK, Kapadia JR. Current knowledge on biodegradable microspheres in drug delivery. Expert Opin Drug Delivery 2015;12:1283-99.

8. Doty AC. Mechanistic analysis of in vivo and in vitro drug release from PLGA Microspheres. Ph. D. Thesis, University of Michigan, Ann Arbor, ML, USA; 2015.

9. Lengyel M, Kallai Sazabo, N Microparticles. Microspheres and microcapsules for advanced drug delivery. Sci Pharm 2019;87:1-31.

10. Senthil A. Mucoadhesive microspheres. Int J Pharm Res Ayurveda Pharm 2011;2:55-9.

11. Lohani A, Chaudhary GP. Mucoadhesive microspheres: a novel approach to increase gastroretention. Chron Young Sci 2012;3:121-8.

12. Deshmukh MT, Mohite SK. Preparation and evaluation of mucoadhesive microsphere of fluoxitine HCL. Int J Pharm Sci Res 2017;8:3776-85.

13. Singh I, Kamboj S, Rana V. Quality by design based fabrication of iron oxide induced mucoadhesive microspheres for enhanced bioavalibility of cinnarizine. Curr Drug Delivery 2017;14:1154-69.

14. Farah FH. Magnetic microsphers: a noval drug delivery system. J Anal Pharm Res 2016;3:00067.

15. Kakar S, Batra D, Singh R, Nautiyal U. Magnetic microspheres as magical novel drug delivery system: a review. J Acute Disease 2013;2:1-12.

16. Kawatra M, Jain U, Ramana J. Recent advances in floating microspheres as gastroretentive drug delivery system: a review. Int J Recent Adv Pharm Res 2012;2:5-23.

17. Mukund JY, Kantilal BR, Sudhakar RN. Floating microspheres: a review. Braz J Pharm Sci 2012;48:17-30.

18. Bhadouriya P, Kumar M, Pathak K. Floating microspheres: to prolong the gastric retention time in stomach. Curr Drug Delivery 2012;9:315-24.

19. Negi M, Shukla VK, Easwari TS. Overview on recent researches on floating microspheres. J Pharm Biosci 2014;2:25-33.

20. Sinha VR, Goyel V, Trehan A. Radioactive microspheres in therapeutics. Pharmazie 2004;59:419-26.

21. Hafeli U. Radioactive microspheres for medical applications. In: De Cuyper M, Bulte JWM. editors. Physics and Chemistry Basis of Biotechnology. Focus on Biotechnology. Netherlands: Kluwer Academic Publisher; 2001. p. 213-48.

22. Wang SJ, Lin WY, Chen MN, Hsieh BT, Shen LH, Tsai ZT, et al. Rhenium-188 microspheres: a new radiation synovectomy agent. Nucl Med Commun 1998;19:427-33.

23. Kennedy AS. Radioactive microspheres for liver cancers. US Oncol Rev 2005;1:25-8.

24. Davis SS, Illum L. Polymeric microspheres as drug carriers. Biomaterials 1988;9:111-2, IN5, 113-5.

25. Prasanth VV, Moy AC, Mathew S, Rinku M. Microspheres-an overview. Int J Res Pharm Biomed Sci 2011;2:332-8.

26. Saralidze K, Koole LH, Knetsch MLW. Polymeric microspheres for medical applications. Materials (Basel) 2010;3:3537-64.
27. Patel NR, Patel DA, Bharadia PD, Pandya VM, Modi D. Microsphere as novel drug delivery. Int J Pharm Life Sci 2011;2:992-7.

28. Pavan KB, Chandiran IS, Bhavya B, Sindhuri M. Microparticulate drug delivery system: a review. Indian J Pharm Sci Res 2011;1:19-37.

29. Sinha VR, Singla AK, Wadhawan S. Chitosan microspheres as a potential carrier for drugs. Int J Pharm 2004;274:1-33.

30. Mokhtare B, Cetin M, Ozakar RS, Bayrakceken H. Preparation of metformin $\mathrm{HCl}-$ loaded chitosan microspheres and in vitro characterization studies. Hacettepe University J Faculty Pharm 2015;35:74-86

31. Sinha VR, Bansal K, Kaushik R. Polycaprolactone microspheres and nanosphere's. Int J Pharm 2004;278:1-23.

32. Jain NK. Controlled and novel drug delivery. 4th Ed. New Delhi: CBS Publishers; 2006. p. 236-7.

33. Gohel MC, Parikh RK, Nagori SA, Gandhi AV, Shroff MS, Patel PK, et al. A spray drying a review. Pharm Rev 2009;7;2-23.

34. Parikh D. Spray drying as a granulation technique. In: Handbook of Pharmaceutical Granulation Technology, Drugs and the Pharmaceutical Sciences. New York: Marcel Dekker; 1997. p. 75-96.

35. Swarbrick BJ. Spray drying and spray congealing of pharmaceuticals. In: Encyclopedia of Pharmaceutical Technology. New York Marcel Dekker; 1992. p. 207-21.

36. Sinha VR, Bansal K, Kaushik R. Polycaprolactone microspheres and nanosphere's. Int J Pharm 2004;278:1-23.

37. He P, Davis SS, Illum L. Chitosan microspheres prepared by spray drying. Int J Pharm 1999;187:53-65.

38. Christina E. Prepration of microspheres of diclofenac sodium by ionotropic gelation technique. Int J Pharm Pharm Sci 2012;5:228-31.

39. McGinity JW, O'Donnell PB. Preparation of microspheres by the solvent evaporation technique. Adv Drug Delivery Rev 1997;28:25-42.

40. Sudhamani T, Reddy N, Ravi Kumar V, Revathi R, Ganesan V. Preparation and evaluation of ethyl cellulose microspheres of ibuprofen for sustained drug delivery. Int J Pharm Res Dev 2010;2:119-25.

41. Merkel HP, Speister P. Preparation and in vitro evaluation of microspheres using cellulose acetate phthalate. J Pharm Sci 1973;62:1444-8.

42. Rahman M, Islam M, Sharmin N, Chowdhury J, Jalil R. Preparation and evaluation of cellulose acetate phthalate and ethyl cellulose-based microcapsules of diclofenac sodium using emulsification and solvent evaporation method. Dhaka University J Pharm Sci 2010;9:39-46.

43. Chaturvedi K, Kulkarni AR, Aminabhavi TM. Blend microspheres of poly(3-hydroxybutyrate) and cellulose acetate phthalate for colon delivery of 5-fluorouracil. Ind Eng Chem Res 2011;50:10414-23.

44. Beyger JW, Nair JG. Some factors affecting the microencapsulation of pharmaceuticals with cellulose acetate phthalate. J Pharm Sci 1986;75:573-8.

45. Farid DJ, Nokhodchi A. Dissolution of compacted aspirin microcapsules. Ind J Pharm Sci 1991;53:222-3.

46. Maharaji I, Nairn JG, Cambell JB. Simple rapid method for the preparation of enteric-coated microcapsules. J Pharm Sci 1984;73:39-42.

47. Lin CY, Lin SJ, Yang YC, Wang DY, Cheng HF, Yeh MK. Biodegradable polymeric microsphere-based vaccines and their applications in infectious diseases. Hum Vaccin Immunother 2015;11:650-6.

48. Kohn J, Niemi SM, Albert EC, Murphy JC, Langer RS, Fox JG. Single-step immunization using a controlled release, biodegradable polymer with sustained adjuvant activity. J Immunol Methods 1986;95:31-7.

49. Gupta RK, Singh M, O'Hagan DT. Poly(lactide-co-glycolide) microparticles for the development of single-dose controlledrelease vaccines. Adv Drug Delivery Rev 1998;32:225-46.

50. Nellore RV, Pande PG, Young D, Bhagat HR. Evaluation of biodegradable microspheres as vaccine adjuvant for Hepatitis B surface antigen. J Parenteral Sci Tech 1992;46:176-80. 
51. Desai KG, Schwendeman SP. Active self-healing encapsulation of vaccine antigens in PLGA microspheres. J Controlled Release 2013;165:62-74.

52. Cui Y, Cui P, Chen B, Li S, Guan H. Monoclonal antibodies: formulations of marketed products and recent advances in novel delivery system. Drug Dev Ind Pharm 2017;43:519-30

53. Sailaja AK, Anusha K, Jyothika M. Biomedical applications of microspheres. J Modern Drug Discovery Drug Delivery Res 2015;4:1-5.

54. Adamson P, Wilde T, Dobrzynski E, Sychterz C, Polsky R, Kurali $\mathrm{E}$, et al. Single ocular injection of a sustained-release anti-VEGF delivers 6 mo pharmacokinetics and efficacy in a primate laser CNV model. J Controlled Release 2016;244:1-13.

55. Stern M, Ulrich K, Geddes DM, Alton EWFW. Poly (D, L-lactideco-glycolide)/DNA microspheres to facilitate prolonged transgene expression in airway epithelium in vitro, ex vivo and in vivo. Gene Ther 2003;10:1282-8.

56. Liu W, Borrell MA, Venerus DC, Mieler WF, Kang Mieler JJ. Characterization of biodegradable microsphere-hydrogel ocular drug delivery system for controlled and extendedrelease of ranibizumab. Curr Eye Res 2018;44:264-74.

57. Lubben IMVD, Kersten G, Fretz MM, Beuvery C, Verhoef JC, Junginger HE. Chitosan microparticles for mucosal vaccination against diphtheria: oral and nasal efficacy studies in mice. Vaccine 2003;21:1400-8.

58. Rathananand M, Kumar DS, Shirwaikar A, Kumar R, Kumar S, Prasad RS. Preparation of mucoadhesive microspheres for nasal delivery by spray drying. Indian J Pharm Sci 2007;69:651-7.

59. Pereswetoff Morath L. Microspheres as nasal drug delivery systems. Adv Drug Delivery Rev Adv Drug Delivery Rev 1998;29:185-94.

60. Nigam J, Pandey P, Mishra MK. Formulation and evaluation of anti-emetic microspheres for nasal drug delivery system. Indian J Novel Drug Delivery 2017;9:44-53.

61. Saez VC, Hernandez JR, Peniche C. Microspheres as delivery systems for the controlled release of peptides and proteins. Biotecnol Aplicada 2007;24:108-16.

62. Ma G. Microencapsulation of protein drugs for drug delivery: strategy, preparation, and applications. J Controlled Release 2014;193:324-40.

63. Thundimadathil J. Peptide therapeutics: strategy and tactics for chemistry manufacturing and controls. In: Srivastava V. editor. Formulations of microspheres and nanoparticles for peptide delivery. 1st edition. Cryodon: Royal Society of Chemistry; 2019. p. 503-30.

64. Rajput MS, Agrawal P. Microspheres in cancer therapy. Indian J Cancer 2010;47:458-68.

65. Midha K, Nagpal M, Arora S. Microspheres: a recent update. Int J Recent Sci Res 2015;6:5859-67.
66. Singh A, Sharma PK, Malviya R. Sustained drug delivery using mucoadhesive microspheres: the basic concept, preparation methods and recent patents. Recent Patents Nanomed 2012;2:62-77.

67. Mishra N, Goyal AK, Khatri K, Vaidya B. Biodegradable polymer based particulate carrier(s) for the delivery of proteins and peptides. Anti-Inflammatory Anti-Allergy Agents Med Chem 2008; 7:240-51.

68. Jin T, Hu Z, Yuan W. Microspheres for controlled-or sustainedrelease delivery of therapeutics. U. S. Patent numberUS9381159B2; 2016

69. Lewis AL, Tang Y, Stratford PW. Microspheres for treatment of brain tumors, US 8,691,791 B2; 2014.

70. Singh A, Singh S, Puthli S, Tandale R. Programmable buoyant delivery technology. U. S. Patent number US 8,277,843 B2; 2012.

71. Chandler DJ, Austin Bedre J. Magnetic microspheres for use in fluorescence-based applications. U. S. Patent Number US 7,718,262 B2; 2010.

72. Ilum L, Ping $\mathrm{H}$. Gastroretentive controlled-release microspheres for improved drug delivery. U. S. Patent number US 6,207,197 B1; 2001.

73. Margel S. Metal-coated polyaldehyde microspheres, U. S. Patent Number US 4,624,923; 1986

74. Li S, Dynan WS, Wicks G, Serkiz S. Porous wall hollow glass microspheres as carrier for biomolecules. U. S. Patent Number US 8,535,725 B2; 2013.

75. Mathiowitz E, Chickering D, Jacob JS. Bioadhesive microspheres and their use as drug delivery and imaging, Patent number US 6,235,313 B1; 2001.

76. Walt DR, Mandal TK, Fleming MS. Polymeric microspheres, U. S. Patent Number US 6,720,007 B2; 2004.

77. Billot GB, Teichner MM. Process for preparing microspheres for prolonged release of the LHRH hormone and its analogues, microspheres and formulations obtained, U. S. Patent number US 5,540,937; 1996.

78. Brown LR. Production of microspheres, patent number US 7,374,782 B2; 2008.

79. Barrow WW, Barrow EL, Quenelle DC, Winchester GA, Staas JK. Compositions and methods for treating intracellular infections. U. S. Patent number-US 6,264,991 B1; 2001.

80. Wani SUD, Gangadharappa HV, Ashish NP. Formulation, development and characterization of drug delivery systems based telmisartan encapsulated in silk fibroin nanosphere's. Int J Appl Pharm 2019;11:247-54.

81. Wani SUD, Gangadharappa HV. Silk fibroin based drug delivery applications: promises and challenge. Curr Drug Targets 2018;19:1177-90. 